\title{
Environmental Monitoring Systems: A Review
}

\author{
Anuj Kumar, Hiesik Kim, and Gerhard P. Hancke, Senior Member, IEEE
}

\begin{abstract}
This review article discusses various techniques of environmental monitoring (EM) systems and what is required for the variations in hardware implementation and/or algorithmic logic. This review presents an overview of the existing stateof-the-art practices of environmental monitoring systems and is mainly focused on energy-efficient and low-cost environment monitoring systems. The following are some of the major factors that usually rule the development of EM systems, namely, energy efficiency, cost of the overall system, response time of the sensor module, good accuracy of the system, adequate signal-to-noise ratio, radio frequency interference/electromagnetic interference (RFI/EMI) rejection during varying atmospheric conditions and in inhomogeneous environments, a user friendly interface with the computer, and complexity of computation. The above concerns are also recognized by reference to research articles on environmental monitoring systems. Emphasis is on the necessity of robust systems that address all or most of the above mentioned criteria.
\end{abstract}

Index Terms - Electrochemical/semiconductor sensor, environmental monitoring, IEEE 1451, network capable application processor, smart transducer interface module, transducer independent interface.

\section{INTRODUCTION}

$\mathbf{E}$ NERGY consumption and efficiency have now become an important concern for sustained economic growth and overall development [1]. For a developing country, like South Africa, the situation is further aggrieved because a major part of energy to drive the economy is imported [2]. Today it is widely accepted that human activities are responsible for a high level of pollution and climate change. According to the $4^{\text {th }}$ Intergovernmental Panel on Climate Change (IPCC) report, global greenhouse gas emissions from 1970-2004 due to human activities rose by $70 \%$ [3]. The United Nations Environment Programme (UNEP) report states that buildings are using the lion's share (40\%) of the available global energy and are responsible for one third of global greenhouse gas emissions, both in developed and developing countries [1]. The main source of greenhouse gas emissions from buildings is energy consumption. Buildings are also major emitters of other non- $\mathrm{CO}_{2}$ greenhouse gases.

The life cycle cost analysis (LCA) approach reveals that over $80 \%$ of greenhouse gas emissions take place during

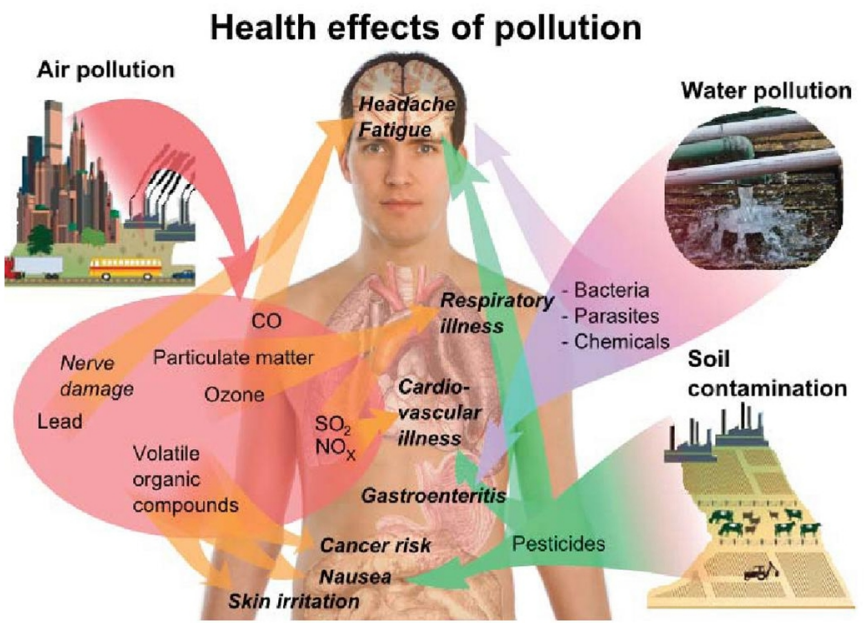

Fig. 1. Representation of health effects due to pollution [6]-[8].

the operational phase of buildings, where energy is being used for heating, cooling, ventilation, lighting, appliances and other applications [4]. A smaller percentage of emissions, roughly from $10-20 \%$, are due to manufacturing of materials, construction, maintenance, renovation, transportation, and demolition [1]. Major greenhouse pollutants include $\mathrm{CO}_{2}, \mathrm{CO}$, $\mathrm{SO}_{\mathrm{X}}, \mathrm{NO}_{\mathrm{X}}$, suspended particulate matter (SPM), lead aerosol, volatile organic compounds and other toxics. These gases are mainly produced by industries, automobile, agriculture activities, and even ordinary homes [5]. From different studies, it is well documented that when human beings come in contact, these chemicals/pollutants have adverse effects on human health. These chemicals are responsible for diseases, like lung cancer, pneumonia, asthma, chronic bronchitis, coronary artery disease and chronic pulmonary disease. Fig. 1 represents the health effects due to pollution, such as air pollution, water pollution, and soil contamination and demonstrates that air pollution is a major environmental risk to health [6]-[8].

To reduce greenhouse gas emissions and to provide a better environment to the occupants, it becomes necessity that the environment should be continuously monitored [9]. Studies show that by constant monitoring and using commercially available technologies, it is possible to reduce carbon emissions by $60 \%$ or more, which translates to 1.35 billion tons of carbon [10]. The environment has become an important area of research because of its influence on human health and on the energy consumption profile. The unconditioned environment affects the indoor physical environment, and subsequently the health and quality of life of building occupants [11]. Achieving occupant comfort is the result of a combination of environmental conditions, such as air quality, indoor air temperature, relative humidity, mean radiant temperature, air velocity, illumination, sound level, etc. Of these, the most important factors 


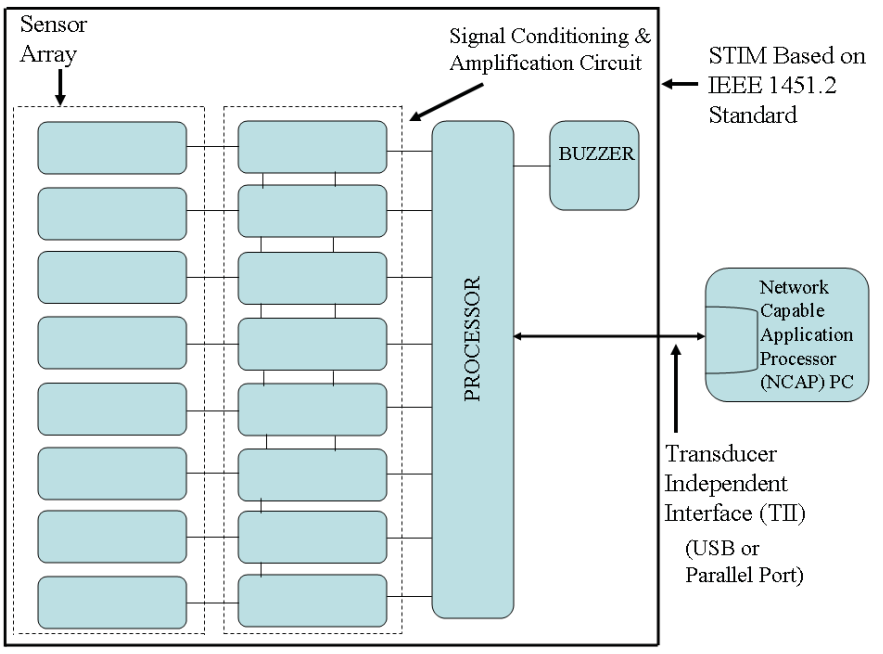

Fig. 2. Environmental monitoring system [15], [26].

are air quality and indoor physical environment [12]. If these are ignored, discomfort will be felt, which in turn will lead to physiological stress affecting human health [10]-[13].

There is a growing demand for environmental monitoring and control systems [14]-[25]. In view of ever increasing pollution sources with toxic chemicals, these systems should have the facilities to detect and quantify the sources of pollution rapidly [26], [27]. The environmental monitoring system desired is a complete, real-time monitoring and data recording system. It automatically measures and records air quality and environmental parameters. The environmental monitoring system comprises three main components - namely, a Standard Transducer Interface Module (STIM), Graphical User Interface (GUI), and Transducer Independent Interface (TII). The STIM module is intensively used for measuring and storing data whereas the GUI is used to read and save data in text files, interpret, and display the results in digital and graphical wave forms, and the TII is used for communication between STIM and the Network Capable Application Processor (NCAP) [14]-[28]. The monitoring system is a complete data acquisition system with sensor array(s) coupled to a data storage device [29]. An environmental monitoring system is shown in Fig. 2.

Some researcher has been explained the automatic measurement system based on wireless sensor network in different areas, such as remote sensing and control of irrigation system [21]; in-situ monitoring of Debris flows [22]; cold chain monitoring for food products [23]; cognitive approach of volatile organic compounds (VOC) [24], [25]. This review article presents an overview of the existing state-of-the-art practices for environmental monitoring systems and is mainly focused on energy-efficient and low-cost environmental monitoring systems that are portable, have fast response time, and are easy to operate.

\section{Standard Transducer Interface MODULE (STIM)}

The IEEE 1451-based Standard Transducer Interface Module (STIM) that contains Transducer Electronic Data Sheets

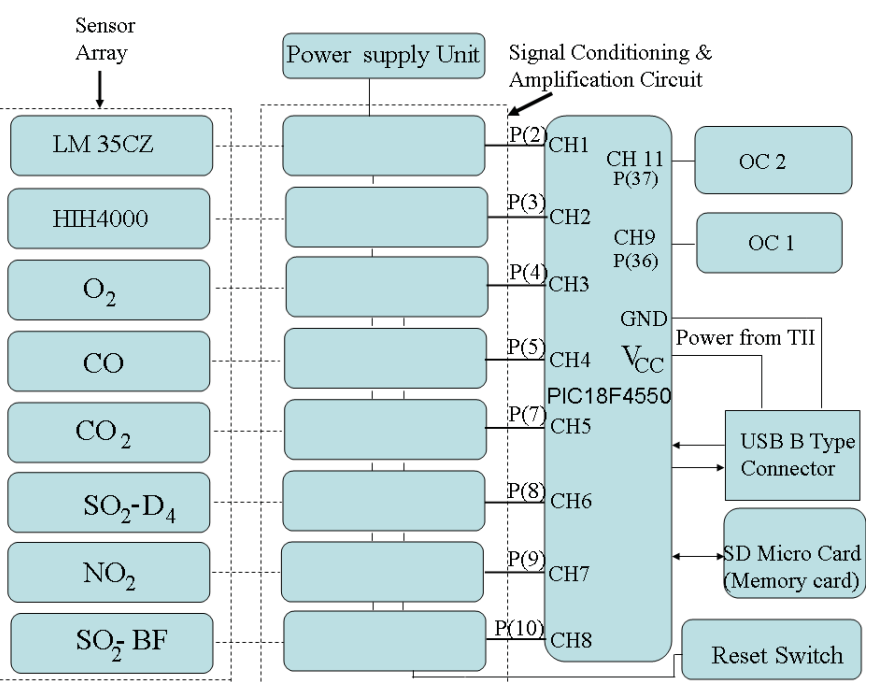

Fig. 3. Block diagram of the standard transducer interface module [28] (see Table I for sensor specifications).

TABLE I

SPECIFICATIONS OF THE SENSORS USED IN THE EMS

\begin{tabular}{|c|c|c|c|}
\hline Sensor Name & Manufacturer & Type of Sensor & Refer. \\
\hline $\begin{array}{c}\mathrm{LM} 35 \mathrm{CZ} \\
\text { Temp. sensor }\end{array}$ & $\begin{array}{c}\text { National } \\
\text { Semiconductor, USA }\end{array}$ & Semiconductor & 28 \\
\hline $\begin{array}{c}\mathrm{HIH}-4000 \\
\text { Humidity sensor }\end{array}$ & Honeywell, USA & Semiconductor & 28 \\
\hline $\mathrm{CO}-\mathrm{CF}$ & Alphasense, UK & Electrochemical & $19,28,34$ \\
\hline $\mathrm{CO}_{2}$-D1 & Alphasense, UK & Electrochemical & $19,34,63$ \\
\hline $\mathrm{SO}_{2}$-D4 & Alphasense, UK & Electrochemical & 19,34 \\
\hline $\mathrm{O}_{2}-\mathrm{A} 1$ & Alphasense, UK & Electrochemical & 19,34 \\
\hline $\mathrm{NO}_{2}-\mathrm{A} 1$ & Alphasense, UK & Electrochemical & 19,34 \\
\hline $\mathrm{SO}_{2}$-BF & Alphasense, UK & Electrochemical & 19,34 \\
\hline $\mathrm{CO}$ & Figaro, Japan & Semiconductor & 15,19 \\
\hline $\mathrm{CO} 2$ & Figaro, Japan & Semiconductor & 15,19 \\
\hline $\mathrm{SO} \mathrm{O}_{2}$ & Figaro, Japan & Semiconductor & 15,19 \\
\hline $\mathrm{O}_{3}$ & Figaro, Japan & Semiconductor & 15,19 \\
\hline VOC & - & - & 19 \\
\hline $\mathrm{TGS} 832^{\mathrm{TGS} 822}$ & Figaro, Japan & Semiconductor & 13 \\
\hline & Figaro, Japan & Semiconductor & 24,25 \\
\hline
\end{tabular}

(TEDS), the Transducer Independent Interface (TII), the transducer(s) and/or connection to the transducer(s), and any signal conversion or signal conditioning [26]. A transducer that provides functions beyond those necessary for producing a correct representation of the sensed quantity is desirable. This functionality typically simplifies the integration of the transducer into applications in a networked environment. The block diagram of the IEEE 1451.2 standard-based Standard Transducer Interface Module is shown in Fig. 3 [28].

\section{A. Sensor Array}

A sensor array is a group of sensors and a sensor is a device that detects a physical quantity and responds with an electrical signal. A gas sensor is a transducer which converts input energy of one form into output energy of another form in response to the presence of a gas; it detects gas molecules 


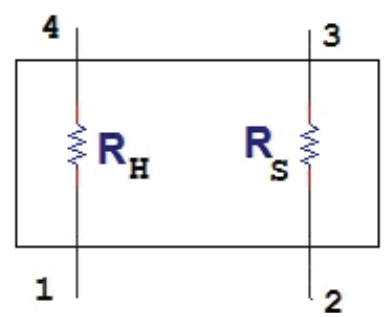

Fig. 4. Basic semiconductor sensor equivalent structure [13]. $\mathrm{R}_{\mathrm{H}}$ : heater element resistence. $\mathrm{R}_{\mathrm{S}}$ : source resistence.

and produces an electrical signal with a magnitude related to the concentration of the gas [28]. Previously there was no gas sensor which was $100 \%$ sensitive to a particular gas. Recently, a few researchers have reported gas sensors with improved performance [15]-[19]. There are five commonly used technologies for monitoring gases. These are: electrochemical, solid state, infrared, catalytic bead, and photoionization [19]. More details of these sensors including their usage, life time, advantages and disadvantages are reported in the literature [30]-[36]. These sensors are being extensively used in various applications like automotive, consumer, commercial, industrial and environmental monitoring [37], [38]. Advantageoussensors for environmental monitoring systems are given in Table I.

1) Semiconductor Sensors: A semiconductor sensor consists of one or more metal oxides (tin oxide, aluminum oxide, etc.). When heated to a high temperature, an n-type semiconductor material decreases its resistance in a reducing environment and increases its resistance in an oxidizing environment, while a p-type semiconductor increases its resistance in the presence of a reducing gas and decreases its resistance in an oxidizing environment [15].

Typically, a semiconductor sensor produces a strong signal, especially at high gas concentrations [15] with adequate sensitivity, fast response time, long term stability, and long life. However, the main disadvantage is the lack of selectivity and relatively high power consumption. Fig. 4 represents the basic structure of semiconductor gas sensors.

a) Theory of operation: The conductivity of the sensing element, which is formed by a metal-oxide semiconductor material, changes according to gas concentration. For example, in an n-type $\mathrm{SnO}_{2}$ sensing material, when the $\mathrm{SnO}_{2}$ crystal is heated to a certain temperature in air, oxygen is absorbed at the solid-gas interface of the sensor and forms surface oxygen ions with negative charge, creating a potential barrier against electron flow between $\mathrm{SnO}_{2}$ particles. This potential barrier increases the resistivity of the material preventing carriers from moving freely.

In the presence of a reducing gas, the surface density of the negative oxygen's ions decreases. Consequently, the height of the potential barrier decreases and as a result, the resistivity of the material falls logarithmically. This characteristic is illustrated in Fig. 5.

The correlation between the sensor resistance $\left(\mathrm{R}_{\mathrm{S}}\right)$ and the concentration of a reducing gas $(\mathrm{C})$ can be expressed by the

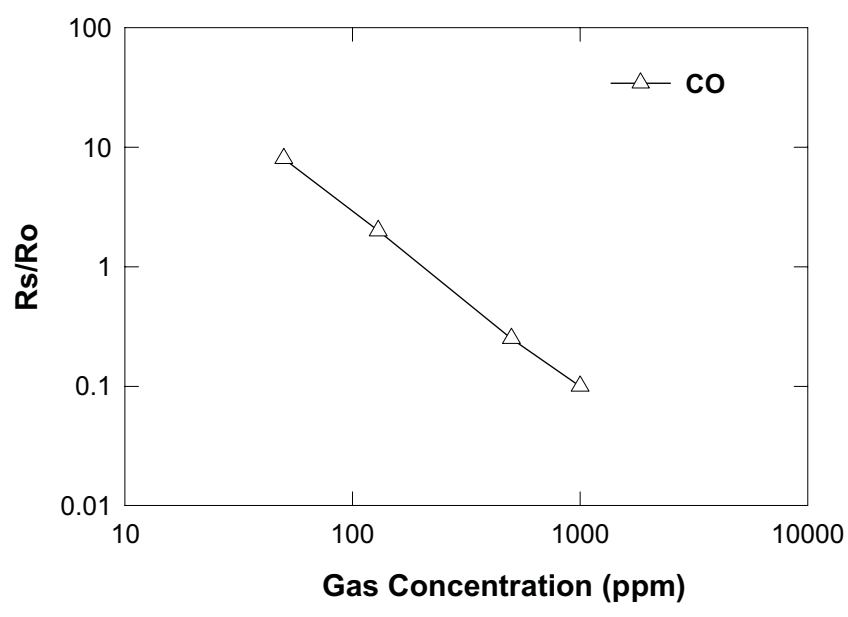

Fig. 5. Typical sensitivity characteristics of $\mathrm{SnO}_{2}$-based $\mathrm{CO}$ sensor [15].

following general function [15]

$$
R_{S}=R_{0}(1+I \sqrt{C})
$$

where Rs $=$ electrical resistance of the sensor; $\mathrm{R}_{0}=$ electrical resistance of sensor at zero ppm of reducing gas; $\mathrm{I}=$ a constant for a particular sensor; $\mathrm{C}=$ gas concentration (in ppm).

2) Electrochemical Gas Sensors: Electrochemical sensors are used to determine the concentration of various analyte compounds in testing samples, such as fluids and dissolved solid materials [38]. Electrochemical sensors are frequently used in occupational safety, medical engineering, process measuring measurement/control, environmental analysis, etc. [39]. Electrochemical sensors have electrode arrays with two, three or more electrodes, which are called auxiliary electrodes, reference electrodes, and working electrodes [40], [41]. Electrochemical gas sensors are well known for detecting and quantifying toxic gases, such as carbon monoxide, hydrogen sulphide, nitrogen oxides, chlorine, sulphur dioxide and the like. The electrodes of an electrochemical sensor provide a surface on which an oxidation or a reduction reaction occurs to provide a mechanism whereby the ionic conduction of an electrolyte solution in contact with the electrodes is coupled with the electron conduction of each electrode to provide a complete circuit for the current [38], [42]. In a typical electrochemical gas sensor, the gas to be measured passes from the atmosphere into the sensor housing through a gas permeable membrane and onto a working electrode where a chemical reaction occurs [43]. Electrochemical sensors, such as $\mathrm{pH}$ sensors, ion selective sensors, and redox sensors, are equipped with electrical conductors to allow electrical signals to be transmitted to and from electrodes contained within the sensor. An electrochemical sensor used for measuring $\mathrm{pH}$, ORP (oxidation/reduction potential), or other specific ion concentrations typically is comprised of three parts: namely, a specimen sensing ion electrode, a reference cell, and an amplifier that translates signal into useable information that can be read [44].

Electrochemical sensors require very little power to operate. In fact, their power consumption is the lowest among all other sensor types available for gas monitoring. Moreover, they are 


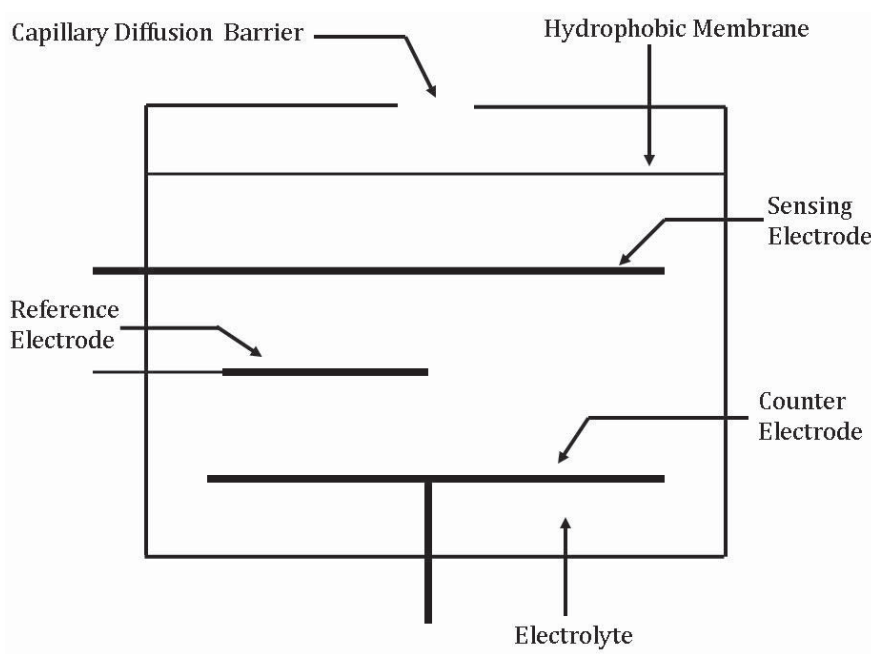

Fig. 6. Basic electrochemical sensor structures [38], [42].

very linear and have good selectivity, excellent repeatability, and good accuracy [39]. For these reasons, these sensors are widely used in portable instruments that contain multiple sensors. They are one of the most popular sensors being used in confined space environment applications and for indoor environment monitoring of buildings [28]-[45]. However, their disadvantages include shortened lifetime in very dry areas, sensitivity to EMF/RFI, limited storage life, and long response times. These disadvantages can be rectified by using special strategies [42]-[45].

a) Theory of operation: Electrochemical sensors operate by reacting with the gas of interest, producing an electrical signal related to the gas concentration. A typical electrochemical sensor consists of a sensing electrode (working electrode), a reference electrode, and a counter electrode separated by thin layer of electrolyte, as shown in Fig. 6 [38]-[42].

A gas that comes in contact with the sensor first passes through a small capillary type opening, then diffuses through a hydrophobic barrier, and eventually reaches the electrode surface. This approach is adopted to allow the proper amount of gas to react at the sensing electrode to produce a sufficient electrical signal, while preventing the electrolyte from leaking out of the sensor.

The gas that diffuses through the barrier reacts at the surface of the sensing electrode; the reaction involves either an oxidation or a reduction mechanism. These reactions are catalyzed by electrode materials specifically developed for the gas of interest. With a resistor connected across the sensing electrode, a current related to the gas concentration flows between the anode and the cathode. The current can be measured to determine the gas concentration. Because current is generated in the process, the electrochemical sensor is often described as an amperometric gas sensor [46]-[49].

The three-electrode sensors require an external driving voltage. It is important to have a stable and constant potential at the sensing electrode. In reality, the sensing electrode potential does not remain constant due to the continuous electrochemical reaction taking place on the surface of the electrode. It causes a deterioration of the performance of
TABLE II

SPeCification of the SENSOR Module For EM System Adopted B Y RESEARCHERS

\begin{tabular}{|c|c|c|c|c|c|}
\hline $\begin{array}{c}\text { Developed } \\
\text { Sensor } \\
\text { Module }\end{array}$ & $\begin{array}{c}\text { Operating } \\
\text { Voltage }\end{array}$ & $\begin{array}{c}\text { Power } \\
\text { Consump- } \\
\text { tion }\end{array}$ & Range & $\begin{array}{c}\text { Response } \\
\text { Time }\end{array}$ & Refer. \\
\hline $\mathrm{CO}-\mathrm{CF}$ & $\begin{array}{l} \pm 7.0 \mathrm{~V}- \\
\pm 9.0 \mathrm{~V}\end{array}$ & $9.093 \mathrm{~mW}$ & $\begin{array}{c}0.5 \mathrm{ppm}- \\
20 \mathrm{ppm}\end{array}$ & $60 \mathrm{sec}$ & 28 \\
\hline $\mathrm{CO}_{2}-\mathrm{D} 1$ & $\begin{array}{l} \pm 3.0 \mathrm{~V}- \\
\pm 3.3 \mathrm{~V}\end{array}$ & $1.1434 \mathrm{~mW}$ & $\begin{array}{l}50 \mathrm{ppm}- \\
800 \mathrm{ppm}\end{array}$ & 5 minute & 28 \\
\hline $\mathrm{SO}_{2}-\mathrm{D} 4$ & $\begin{array}{l} \pm 2.0 \mathrm{~V}- \\
\pm 3.3 \mathrm{~V}\end{array}$ & $0.72 \mathrm{~mW}$ & $\begin{array}{c}0.04 \mathrm{ppm}- \\
2 \mathrm{ppm}\end{array}$ & $40 \mathrm{sec}$ & 28 \\
\hline $\mathrm{O}_{2}-\mathrm{A} 1$ & $\begin{array}{l} \pm 5.0 \mathrm{~V}- \\
\pm 9.0 \mathrm{~V}\end{array}$ & $3.6292 \mathrm{~mW}$ & $15 \%-65 \%$ & 5 minute & 28 \\
\hline $\mathrm{NO}_{2}-\mathrm{A} 1$ & $\begin{array}{l} \pm 7.0 \mathrm{~V}- \\
\pm 9.0 \mathrm{~V}\end{array}$ & $11.2712 \mathrm{~mW}$ & $\begin{array}{c}0.01 \mathrm{ppm}- \\
0.5 \mathrm{ppm}\end{array}$ & 1 minute & 28 \\
\hline $\mathrm{SO}_{2}-\mathrm{BF}$ & $\begin{array}{l} \pm 7.0 \mathrm{~V}- \\
\pm 9.0 \mathrm{~V}\end{array}$ & $12.722 \mathrm{~mW}$ & $\begin{array}{c}0.04 \mathrm{ppm}- \\
5 \mathrm{ppm}\end{array}$ & $60 \mathrm{sec}$ & 28 \\
\hline $\mathrm{CO}$ & - & - & $0-400 \mathrm{ppm}$ & - & 15 \\
\hline $\mathrm{NO}_{2}$ & - & - & $0-5 \mathrm{ppm}$ & - & 15 \\
\hline $\mathrm{SO}_{2}$ & - & - & $1-10 \mathrm{ppm}$ & - & 15 \\
\hline $\mathrm{O}_{3}$ & $0-+1 \mathrm{~V}$ & $1 \mathrm{~W}$ & $0-100 \mathrm{ppb}$ & $60 \mathrm{sec}$ & 15 \\
\hline LM35CZ & $\pm 5.0 \mathrm{~V}$ & $1.7673 \mathrm{~mW}$ & $\begin{array}{l}15^{\circ} \mathrm{C}- \\
70^{\circ} \mathrm{C}\end{array}$ & $2 \mathrm{sec}$ & 28 \\
\hline HIH4000 & $5.0 \mathrm{~V}$ & $1 \mathrm{~mW}$ & $0 \%-100 \%$ & $15 \mathrm{sec}$ & 28 \\
\hline
\end{tabular}

the sensor over extended periods of time. To improve the performance of the sensor, a reference electrode is introduced. The reference electrode is placed within the electrolyte in close proximity to the sensing electrode. A fixed stable constant potential is applied to the sensing electrode. The reference electrode maintains the value of this fixed voltage at the sensing electrode. No current flows to or from the reference electrode. The gas molecules react at the sensing electrode and the current flow between the sensing and the counterelectrode is measured. This is typically related directly to the gas concentration. The value of the voltage applied to the sensing electrode is specific to the target gas.

In a three-electrode sensor, there is normally a jumper between the working and reference electrodes. If it is removed during storage, it will take a long time for the sensor to stabilize and be ready to be used. Three-electrode sensors require a bias voltage between the electrodes; however, twoelectrode (positive and negative) sensors do not require any bias voltage. For example, oxygen sensors do not require a bias voltage [42]-[46].

\section{B. Sensor Signal Conditioning/Processing}

The signal conditioning of electrochemical and semiconductor sensors are reported in the literature [13]-[16] and [47]-[50]. The sensor signal conditioning/processing circuit parameters adopted by researchers in last decade are given in Table II.

1) Semiconductor Gas Sensors: Fig. 7 represents the basic measuring circuit for chlorofluorocarbons (CFC) for monitoring semiconductor gas sensor response [13], [16]. Sensor resistance for a measured value of $\mathrm{V}_{\text {out }}$ is given by, $\mathrm{R}_{\mathrm{s}}=$ $\left(\mathrm{V}_{\mathrm{c}} \times \mathrm{R}_{\mathrm{L}} / \mathrm{V}_{\text {out }}\right)-\mathrm{R}_{\mathrm{L}}$. The sensitivity $(\beta)$ is calculated on the 


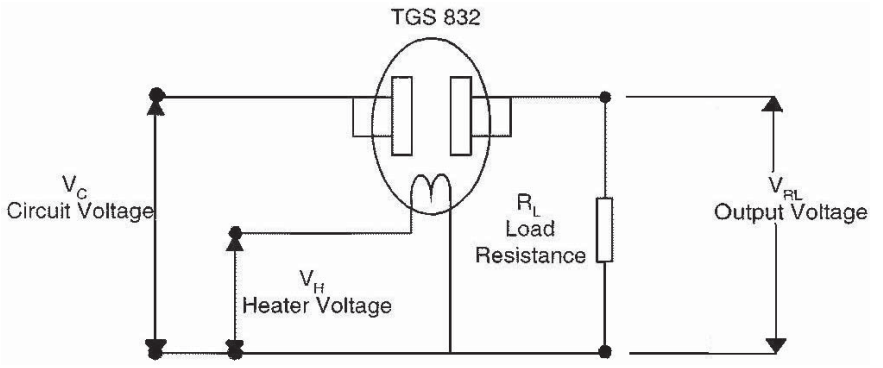

Fig. 7. Schematic diagram of CFC semiconductor gas sensor [13], [16].

basis of two measured values of $\mathrm{R}_{\mathrm{s}}$, and is given by $\beta=$ $\mathrm{R}_{\mathrm{S}}(\mathrm{CO}, 300 \mathrm{ppm}) / \mathrm{R}_{\mathrm{S}}(\mathrm{CO}, 100 \mathrm{ppm})$. The power dissipation is calculated by $P_{S}=(V c)^{2}$. $R_{S} /\left(R_{s}+R_{L}\right)^{2}$. The standard circuit conditions are the heater voltage is $5.0 \mathrm{~V} \pm 0.2 \mathrm{~V}$, the maximum sensing material voltage is $5-24 \mathrm{~V}$ (DC only), and the specification of electrical characteristics are sensor resistance $\mathrm{R}_{\mathrm{S}}(5 \mathrm{k} \Omega-15 \mathrm{k} \Omega)$ and heater resistance $(30 \pm 3 \Omega)$.

2) Electrochemical Sensors: Electrochemical sensors operate by reacting with the monitored gas and producing an electrical current that is linearly proportional to the gas concentration. A potentiostatic circuit is required for the functioning of electrochemical sensors. The potentiostatic circuit consists of three parts: control circuit, current measuring circuit, and one Junction Gate Field-Effect Transistor (JFET) between the working electrode and the reference electrode. The potentiostatic circuit is required to maintain a voltage level between the reference and working electrodes in order to control the electrochemical reaction and to deliver an output signal proportional to the working electrode current. The main advantage of the potentiostatic circuit is that it requires very low power (low power consumption). The performance of the potentiostatic circuit is significantly dependent on the electrical parameters of the amplifier chosen [29]-[44] and [47]-[49]. A circuit diagram of a potentiostatic circuit is shown in Fig. 8.

a) Control circuit: The control op-amp provides the current to the counter-electrode to balance the current required by the working electrode. The inverting input of IC1 is connected to the reference electrode and must not draw any significant current from the reference electrode. The OP90, OP296 and LMP7721 are ultra-low-input bias current op-amps. These assure that the reference electrode will maintain a constant potential by having less than $5 \mathrm{nA}$ of bias current. Normally some toxic gas sensors are operated in the zero bias mode and some sensors, such as NO, require a bias voltage. Sensor cross sensitivity to certain gases can be enhanced by adding a bias voltage. Values of $\mathrm{R}_{1}=\mathrm{R}_{2}=10 \mathrm{k} \Omega ; \mathrm{C}_{1}=10 \mathrm{nF}$ and $\mathrm{C}_{2}=1 \mathrm{nF}$ are chosen for noise reduction and circuit stability, as per recommendations of the manufacturers [47]-[49], as shown in Fig. 8.

b) Current measuring circuit: The measuring circuit is a single stage op-amp (IC2-OP90 or LMP7721) in a transimpedance configuration. When the sensor is exposed to the target gas, such as $\mathrm{CO}$, the reaction at the working electrode oxidizes $\mathrm{CO}$ to $\mathrm{CO}_{2}$, which diffuses out of the sensor.
Hydrogen ions and electrons are generated. The hydrogen ions migrate through the electrolyte towards the counter-electrode. This process leaves a negative charge deposited at the working electrode. Electrons flow out of the working electrode through the resistor $\mathrm{R}_{6}$ to the inverting input of the amplifier (IC2). $\mathrm{C}_{3}$ reduces high-frequency noise. This will convert the signal current from the working electrode into a voltage proportional to the applied gas concentration, such as [49]

$$
\text { Output voltage }=I_{\text {Sensor }} R_{6}
$$

The hydrogen ions that have migrated towards the counterelectrode will increase the potential of the reference and working electrodes. The small rise in potential at the reference electrode is measured by the control amplifier IC1. The amplifier will sink or source an adequate current to the counter-electrode to balance the current required by the working electrode. The measuring circuit is also shown in Fig. 8. The measuring circuit uses a combination of a load resistor $\left(\mathrm{R}_{\mathrm{load}}\right)$ plus internal sensor resistance and the internal sensor capacitance to establish an RC circuit. This RC circuit will affect both the rms noise and the response time. The response time increases linearly with increasing $R_{\text {load }}$ resistance, while noise decreases rapidly with increasing $R_{\text {load }}$ resistance. Therefore the selection of $\mathrm{R}_{\text {load }}$ is a compromise between fastest response time and least noise. Also for high resolution, we have to forego fast response time. Fast response time increases the degradation of the sensor's performance (by increasing the sensor output signal noise). As sensor current flows through $\mathrm{R}_{\text {load}}$, there will be a small change in sensor bias potential. This increases the sensor settling time as the sensor will require a short time to re-stabilize when gas is applied, but transients normally will not be seen except at high gas concentrations and/or with a high $\mathrm{R}_{\text {load }}$ resistance. The value of $R_{\text {load }}$ is chosen so as to achieve noise reduction, a fast response time, and decrease in the sensor settling time. The value of $C_{3}$ reduces high-frequency noise [49], [50]. To re-stabilize a sensor will require a JFET transistor.

c) Functioning of JFET: A p-type JFET is used as a switch to prevent the sensor from polarizing when the circuit has no power. The JFET is only active when power is off; at this time, it shorts the WE (working electrode) and RE (reference electrode) to ensure that the working electrode is maintained at the same potential as the reference electrode. The JFET is active when input bias voltage (V) through a $1 \mathrm{M} \Omega$ resistor is applied. If we do not use a shorting JFET and leave the sensor open when the circuit is turned OFF, the toxic gas sensor will take a few hours to stabilize at the time of next switch ON [48], [50].

The relationship between the output voltage and the gas concentration in ppm can be expressed by the following expressions given in Table III. Table IV represents the architecture of standard transducer interface module adopted by researchers.

Where- $\mathrm{C}_{\mathrm{CO}}$ is - concentration of $\mathrm{CO}$ gas in ppm, $\mathrm{V}_{\mathrm{OUT}-\mathrm{CO}}$ - output voltage of CO-CF sensor module in volts, $\mathrm{C}_{\mathrm{SO}_{2}-\mathrm{D}_{4}-}$ concentration of $\mathrm{SO}_{2}$ gas in ppm, $V_{O U T}-\mathrm{SO}_{2}-D_{4}-$ output voltage of $\mathrm{SO}_{2}-\mathrm{D}_{4}$ sensor module in volts, $\mathrm{C}_{\mathrm{CO}_{2}}-$ concentration of $\mathrm{CO}_{2}$ gas in ppm, $V_{O U T-C O_{2}}$ - output voltage of 


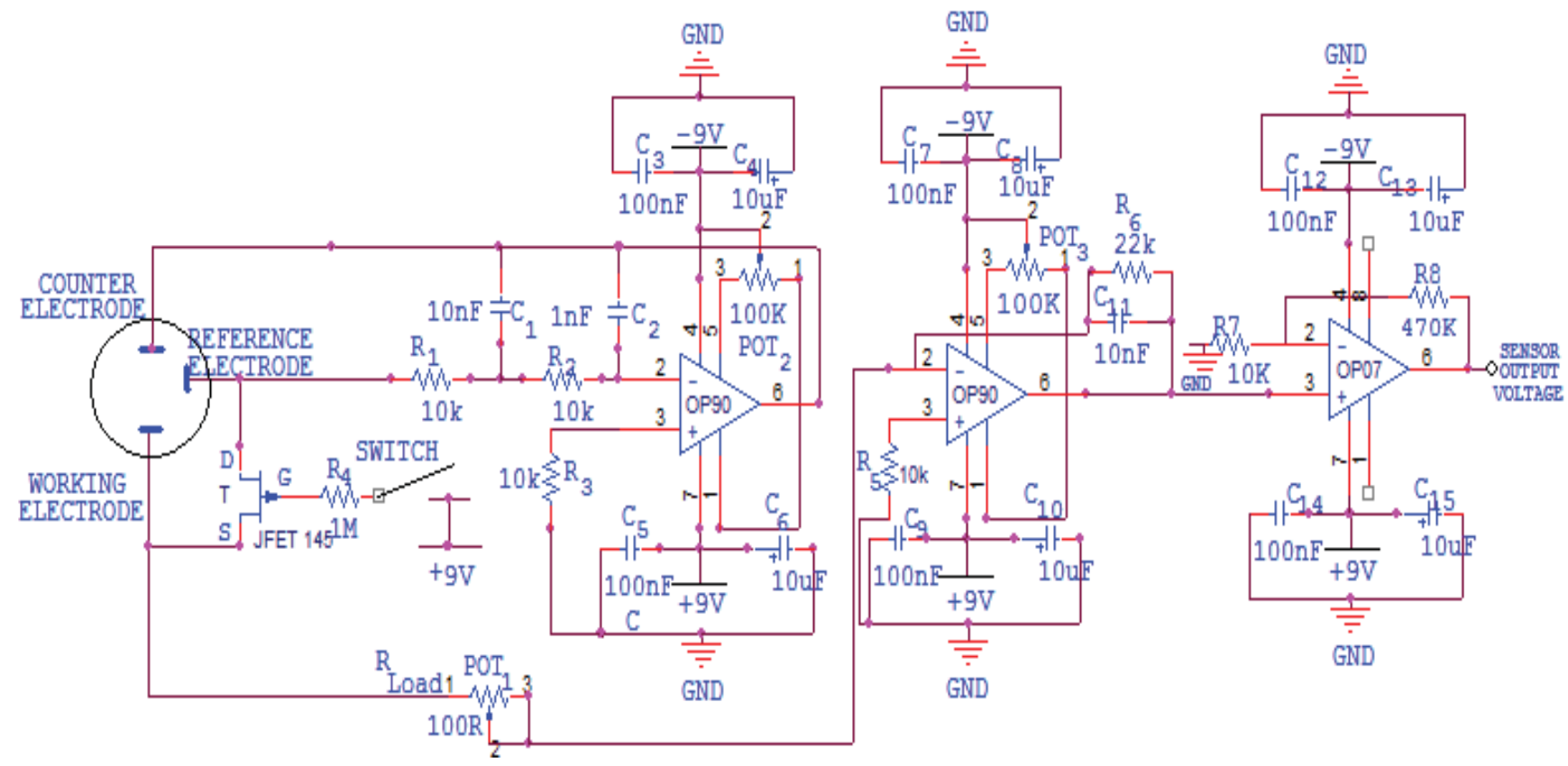

Fig. 8. Schematic diagram of potentiostatic circuit of CO-CF sensor [28], [47], [48].

TABLE III

Mathematical Formulation of the Sensor OUtput Voltage And GAS CONCENTRATION

\begin{tabular}{|c|c|c|}
\hline $\begin{array}{c}\text { Module } \\
\text { Name }\end{array}$ & Mathematical Formula & Refer. \\
\hline $\mathrm{CO}-\mathrm{CF}$ & $C_{C O}(P P M)=4.1 \times V_{O U T-C O}$ & 28 \\
\hline $\mathrm{CO}_{2}-\mathrm{D} 1$ & $C_{C O 2}(P P M)=196.078 \times V_{O U T-C O 2}$ & 28 \\
\hline $\mathrm{SO}_{2}-\mathrm{D} 4$ & $C_{S O 2-D 4}(P P M)=0.055 \times V_{O U T-S O 2-D 4}$ & 28 \\
\hline $\mathrm{O}_{2}-\mathrm{A} 1$ & $C_{O 2}(\%)=13.93 \times V_{O U T-O 2}$ & 28 \\
\hline $\mathrm{NO}_{2}-\mathrm{A} 1$ & $C_{N O 2}(P P M)=0.01046 \times V_{O U T-N O 2}$ & 28 \\
\hline $\mathrm{SO}_{2}-\mathrm{BF}$ & $C_{S O 2}(P P M)=0.04761 \times V_{O U T-S O 2-B F}$ & 28 \\
\hline $\mathrm{LM} 3 \mathrm{CZ}$ & $T\left({ }^{\circ} C\right)=14.2857 \times V_{O U T-L M 35 C Z}$ & 28 \\
\hline $\mathrm{HIH} 4000$ & $R H(\%)=\left[\left(\frac{V_{O U T-H I H 4000}}{3.86}\right)-0.16\right] / 0.0062$ & 28 \\
\hline
\end{tabular}

$\mathrm{CO}_{2}$ sensor module in volts, $\mathrm{C}_{\mathrm{O}_{2}}-$ concentration of $\mathrm{SO}_{2}$ gas in $\%, V_{O U T-O_{2}}-$ output voltage of $\mathrm{O}_{2}$ sensor module in volts, $\mathrm{C}_{\mathrm{NO}_{2}}$ - concentration of $\mathrm{NO}_{2}$ gas in ppm, $\mathrm{V}_{\mathrm{OUT}-\mathrm{NO}_{2}}$ - output voltage $\mathrm{NO}_{2}$ sensor module in volts, $\mathrm{T}$ - indoor environment temperature in ${ }^{\circ} \mathrm{C}, \mathrm{V}_{\text {OUT }}$-LM35CZ - output voltage of temperature module in volts, $\mathrm{RH}$ - indoor relative humidity in \%, $\mathrm{V}_{\mathrm{OUT}-\mathrm{HIH} 4000}$ - output voltage of humidity module in volts, $\mathrm{C}_{\mathrm{SO}_{2}-\mathrm{BF}}$ - concentration of $\mathrm{SO}_{2}$ gas in ppm, $V_{O U T-S O_{2}-\mathrm{BF}^{-}}$ output voltage of $\mathrm{SO}_{2}-\mathrm{BF}$ sensor module in volts.

\section{Network CAPable Application Processor}

The defined NCAP is in accordance with IEEE 1451.1 standard [27]. Its logic components can be divided into two groups, namely; support and application. The components of support are the transducer interface, the network interface, and the operating system. The transducer interface block encapsulates the details of the transducer hardware implementation with a programming model when the NCAP is connected to a STIM. The network interface block encapsulates the details of different network protocol implementations that correspond to a set of communication methods. The operating system, on the other hand, provides an interface with applications. The uses of NCAP include a PC with an USB connection as the hardware component and a software component fully developed in LabVIEW 9.0 [28].

Table V represents the architecture of Network Capable Application Processor module adopted by researchers. Kularatna and Sudantha presented a NCAP module based on Visual Basic 6.0 that displays the digital outputs of $\mathrm{CO}, \mathrm{CO}_{2}$, $\mathrm{SO}_{2}, \mathrm{O}_{3}$, and buzzer information of the NCAP module [15].

The NCAP program has two basic sub-programs - one for controlling the STIM and the other for providing the Graphical User Interface (GUI). The STIM controlling program executes data transport and interrupt request functions. In addition, it also supports TII through a USB 2.0 interface. The GUI displays the STIM information, the output of the sensor module in digital as well as graphical waveform formats and the status of the micro memory card (MMC) or micro SD card. The real time data is saved on the basis of the set value of the sampling frequency. Kumar et al. used NCAP GUI for the samples in the range of $1.0 \mathrm{sec}$ to $100 \mathrm{sec}$ [28]. Moreover, their system also provides the facility to add a user interaction to trigger the STIM and send a functional address to the required channel. The front panel of the indoor environmental monitoring system handles input and outputs functions, while the flowchart describes the workings of the NCAP. The front panel has a knob for setting the time interval, a start button, a data save/start button in MMC, a stop button, and digital 
TABLE IV

ARChitecture of StANDARd Transducer Interface Modules

\begin{tabular}{|c|c|c|c|c|}
\hline Refer. & Sensor Array & Architecture & $\begin{array}{c}\text { Transducer Electronic } \\
\text { Data Sheet (TEDS) } \\
\text { Architecture }\end{array}$ & $\begin{array}{l}\text { Programming } \\
\text { Environment }\end{array}$ \\
\hline 15 & $\mathrm{CO}, \mathrm{NO}_{2}, \mathrm{O}_{3}, \& \mathrm{SO}_{2}$ & $\mathrm{ADuC} 812$ & $\begin{array}{l}\text { TEDS is created in the } \\
640 \text { bytes on chip } \\
\text { flash/EE data memory }\end{array}$ & $\mathrm{C}++$ \\
\hline 16,69 & Two analog sensors (any) & PIC12F877 & Microcontroller memory & $\mathrm{C}++$ \\
\hline 28 & $\begin{array}{c}\text { Temp., Humidity, } \mathrm{O}_{2}, \\
\mathrm{CO}, \mathrm{CO}_{2}, \mathrm{SO}_{2} \mathrm{D}_{4}, \mathrm{NO}_{2}, \\
\mathrm{SO}_{2}-\mathrm{BF}\end{array}$ & PIC18F4550, & Micro SD Card (MMC) & Embedded C \\
\hline 29 & $\begin{array}{l}\text { RTC (PCF8583), Temp. } \\
\text { (DS1820), Humidity, } \\
\text { Pressure, Ozone }\end{array}$ & $18 \mathrm{~F} 8520$ & EEPROM \& MMC & $\mathrm{C}$ \\
\hline 58 & General Purpose & AT89C51 \& AT89C51 & $\begin{array}{l}\text { Microcontroller memory } \\
\text { (Same Operating } \\
\text { Frequency) }\end{array}$ & $\mathrm{C}$ \\
\hline 59,60 & 32 Analog Channel & 8052 & $\begin{array}{l}\text { (i) } 8 \text { Kbytes Flash ROM } \\
\text { for program, } 640 \text { bytes } \\
\text { Flash for data, \& } 256 \\
\text { bytes RAM also for data } \\
\text { (ii) External expansion } \\
\text { Memory } 16 \text { Mbytes }\end{array}$ & $\begin{array}{c}\text { PC software tool in } \\
\text { Delphi }\end{array}$ \\
\hline 64 & $\begin{array}{c}\text { Gas Sensor Array MOS } \\
\text { Chip }\end{array}$ & PIC16F873A & Microcontroller memory & $\mathrm{C}$ \\
\hline 64 & $\begin{array}{l}4 \text { Gas sensors, } 1 \text { Temp., } \\
1 \text { Humidity and } 2 \text { digital } \\
\text { actuators }\end{array}$ & ADuC812 \& Z86E08 & $\begin{array}{c}\text { Two external memory } \\
\text { (512 MB Flash \& } \\
512 \text { MB SRAM) }\end{array}$ & $\mathrm{C}$ \\
\hline 65 & Si Cell & ST62E20 & 24C65EEPROM & $\mathrm{C}++$ \\
\hline 66 & $\begin{array}{l}\text { Humidity, Temp., } \mathrm{CO}_{2}, \\
\& \text { Flying Dust }\end{array}$ & 8051, PDA & PC Memory & $\begin{array}{c}\text { VHDL (VHSIC } \\
\text { Hardware Description } \\
\text { Language) }\end{array}$ \\
\hline 71 & $\begin{array}{c}\text { Butane, Propane, } \\
\text { Methane }\end{array}$ & DSP: TMS320C31 & DSP Board Memory & Embedded C \\
\hline 72 & VOC & DSP: TMS320C31 & DSP Board Memory & Embedded C \\
\hline 73 & MOS Array & PIC 16C73A & Controller Memory & $\begin{array}{c}\text { Visual Basic and } \\
\text { EPOCC }++\end{array}$ \\
\hline 74 & $\begin{array}{c}\text { Resistive \& Piezoelectric } \\
\text { Sensor Array }\end{array}$ & MC68HC705C8A & $\begin{array}{l}\text { EEPROM } \\
2 \mathrm{k} * \mathrm{~B}\end{array}$ & FPGA \\
\hline
\end{tabular}

as well as graphical output. Kumar et al. developed a NCAP module that can operate all eight sensing modules [28].

Ramos et al. presented new hardware and software based on virtual instruments [17]. Tests were conducted on a microcontroller based STIM to check both the STIM's performance and the suitability of a NCAP implemented in LabVIEW. The tests included characterization of each digitizing channel of the STIMs and performance analysis of the system when the STIMs operate the digital outputs and the analog inputs, simultaneously [17].

Grimaldi and Marinov presented and discussed a technique based on a distributed measurement system and summarized the concept of virtual instrumentation. Two different approaches for the distributed measurement system were compared. The first is based on the commercially available LabVIEW environment and second is based on object-oriented programming. Based on this study, they also concluded that an Ethernet network system is cost effective [18].

Xie and Liu presented the design of an air-conditioning system for a university gymnasium [51]. They have also indicated the measurement points for various parameters that are needed for monitoring and controlling the virtual air-conditioning system using LabVIEW. The necessary information database can be established by using a computerized virtual air-conditioning control system for air-conditioning units. The temperature and humidity of the air supply, the temperature and humidity of the indoor air-conditioned room, the temperature and humidity of outdoors as well as the rate of air supply, return air, and fresh air can be measured comprehensively and in real time through a telemetry measurement system [51].

\section{TRANSDUCER INDEPENDENT INTERFACE MODULE (TII)}

The transducer interface module provides communication between the Standard Transducer Interface Module (STIM) and the Network Capable Application Processor (NCAP). One side of TII is connected to the STIM and the other side is interfaced to the NCAP PC (Universal Serial Bus (USB) or parallel port). 


\section{MODULES}

\begin{tabular}{|c|c|c|c|}
\hline Refer. & $\begin{array}{c}\text { GUI } \\
\text { Programming }\end{array}$ & $\begin{array}{c}\text { Measuring } \\
\text { Parameter/Used } \\
\text { Channel }\end{array}$ & $\begin{array}{c}\text { Display Output } \\
\text { Digital/Analog }\end{array}$ \\
\hline 15 & Visual Basic 6.0 & $\begin{array}{c}\mathrm{CO}, \mathrm{NO}_{2}, \mathrm{O}_{3}, \& \\
\mathrm{SO}_{2}\end{array}$ & Digital outputs \\
\hline 16 & LabVIEW 6.1 & $\begin{array}{l}\text { General Purpose } \\
\text { Two analog sensor }\end{array}$ & Digital outputs \\
\hline 28 & LabVIEW 9.0 & $\begin{array}{c}\text { Temp., Humidity, } \\
\mathrm{O}_{2}, \mathrm{CO}, \mathrm{CO}_{2} \\
\mathrm{SO}_{2} \mathrm{D}_{4}, \mathrm{NO}_{2} \\
\mathrm{SO}_{2}-\mathrm{BF}\end{array}$ & $\begin{array}{l}\text { Digital and } \\
\text { Graphical } \\
\text { Waveform }\end{array}$ \\
\hline 29 & $\begin{array}{c}\text { C/C++, C\#, } \\
\text { JAVA, \& OSS } \\
\text { Rython } \\
\text { Finally best result } \\
\text { obtained with } \\
\text { JAVA }\end{array}$ & 10 Channel & PC/Laptop \\
\hline 58 & C & General Purpose & LCD Display \\
\hline 59,60 & $\begin{array}{l}\text { PC software tool } \\
\text { in Delphi }\end{array}$ & 32 Channel & $\begin{array}{c}\text { Connected Any } \\
\text { External Display } \\
\text { Device }\end{array}$ \\
\hline 61,62 & LabVIEW & $\begin{array}{l}\text { 4 Channel, } \\
\text { N- Module }\end{array}$ & $\mathrm{PC}$ \\
\hline
\end{tabular}

Some researchers developed a parallel port interface between the STIM and the NCAP based on the IEEE 1451.2 standard and discussed Serial Peripheral Interface (SPI) data transfer protocols [15], [17], [52]. Table VI represents the architecture of the transducer independent interface reported by various researchers.

Kumar et al. used an IEEE 1451.7 standard - based USB 2.0 interface between the STIM and the NCAP PC [28]. The USB is a four wire interface with two data lines and two power lines. Here the STIM receives power from the USB; hence no external power supply is required. The data transfer rate supported by USB 2.0 may be up to $480 \mathrm{Mb} / \mathrm{sec}$. The data can be transferred on the USB bus in four modes: bulk transfer, interrupt transfer, isochronous transfer, and control transfer. All these modes are based on the IEEE 1394 USB standard [53].

In this study, interrupt based transfers have been used. The interrupt transfers are used to transfer small amounts of data with a high bandwidth, where the data is to be transferred, as quickly as possible without delay, high reliability, low cost, and low power consume. If a USB device requires the attention of the host, it must wait until the host polls it before it can report its need for urgent attention. An interrupt request is queued by the device until the host polls the USB device asking for data. The interrupt packets can be in the size of $1-8$ bytes at low speed, $1-64$ bytes at full speed, and up to 1024 bytes at high speed.

USB 2.0 devices have many advantages, such as no extra power supply required, high speed as compared to other interfaces, automatic device detection, hot pluggable. The maximum power of USB 2.0 in Studio 1458 laptop (Dell) to an external device is limited to $500 \mathrm{~mA}$ at $5.0 \mathrm{~V}$. If the power

\begin{tabular}{|c|c|c|c|}
\hline Refer. & TII & Standard & $\begin{array}{c}\text { Communication } \\
\text { Driver }\end{array}$ \\
\hline 15 & Parallel Port & IEEE1451.2 & C ++ \\
\hline 16 & Parallel Port & IEEE1451.2 & C++ \\
\hline 28 & USB Interface & IEEE1451.7 & VISA \\
\hline 29 & RS232 & - & JAVA \\
\hline 58,68 & RS232 & IEEE1451 & C \\
\hline 59,60 & $\begin{array}{c}\text { Parallel port } \\
\text { interface }\end{array}$ & IEEE1451 & $\begin{array}{c}\text { PC software tool } \\
\text { in Delphi }\end{array}$ \\
\hline $\mathbf{6 1}$ & RS232 & IEEE1451 & C \\
\hline 64 & Parallel interface & IEEE1451.2 & C \\
\hline 65 & $\begin{array}{c}\text { MAX232 (Serial } \\
\text { Communication) }\end{array}$ & - & C ++ \\
\hline 66 & RS232 & - & $\begin{array}{c}\text { VHSIC } \\
\text { Descriparion }\end{array}$ \\
\hline 67 & RS232 & IEEE1451 & C ++ \\
\hline 70 & Internet & IEEE1451.2 & C \\
\hline
\end{tabular}

requirement is more than $500 \mathrm{~mA}$, a separate power supply is required. Some of the PIC18 series microcontrollers can directly support the USB interface [53], [54]. Kumar et al. used the Virtual Instruments Software Architecture (VISA) communication method for the latest USB-based system [28]. VISA is a standard application programming interface (API) for instrument I/O communication. VISA is a means for talking to General Purpose Interface Bus (GPIB), Versa Module Europe Extension for Instrumentation (VXI) or serial instruments. VISA is not Lab-VIEW specific, but is a standard available in many languages [28].

\section{RFI/EMI NOISE OF THE SENSOR}

The sensors can easily detect RFI/EMI or environmental noise. Some noise reduction techniques have been adopted by various researchers. Kumar et al. positioned a thin metal cylinder around the electrochemical sensor which is connected to the ground of the PCB. This cylinder also encloses a thin PVC cylinder that itself encloses the entire sensor for mechanical protection. The measuring and controlling op-amps in a potentiostate are fitted underneath the sensor to utilize the shortest leads $(3 \mathrm{~cm}$ to $6 \mathrm{~cm})$ because of the low impedance and low sensor currents; the electronics are arrayed on a multilayer circuit board which includes a ground plane. Sensor and its associated circuitry are connected through wires with grounding connection to the ground pin of the measuring amplifier [28].

\section{CAlibration of the Sensor}

Some researchers have used olfactory calibrated sensors. But due to the requirements of high precision in the measurements at low concentrations, field calibration of these sensors is essential for accurate measurements [55], [56]. The calibration of the sensors can be accomplished by two methods: static chamber method and dynamic method. The static chamber calibration method was selected to calibrate the sensors of 


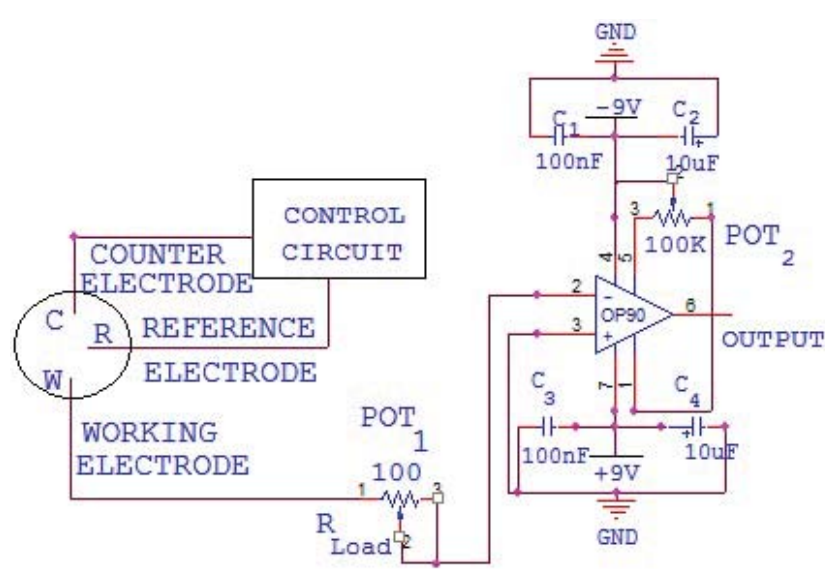

Fig. 9. Schematic diagram of sensor calibration circuit [28].

the array. The static chamber was constructed using inert and silicon-free materials because volatile organic silicones will deteriorate the sensor surface and, hence, degrade the sensor's performance [15]. The calibration procedure has been carried out in two steps: first finding the initial position (zero) of the sensor and second determining the span of the sensor. To find the zero value of sensor, it is required to use "zero air". However, there is no established standard that defines "zero air" [57]. Many laboratories use pure nitrogen or pure synthetic air to calibrate the zero point. By contrast, some others calibrate using ambient air when the area is considered to be clean.

Kularatna and Sudantha [15] presented a calibration of CO, $\mathrm{SO}_{2}$, and $\mathrm{O}_{3}$ semiconductor sensors and used the zero air types. The $\mathrm{CO}$ sensor is calibrated with the bottled synthetic "zero air", while $\mathrm{SO}_{2}$ is calibrated using the clean air in the laboratory. Ambient temperature and humidity of the laboratory were measured daily and the calibration procedure was carried out when the temperature is in the range of $20^{\circ} \mathrm{C}-$ $25{ }^{\circ} \mathrm{C}$, while the relative humidity is the range of $45 \%-50 \%$. This procedure was adopted as there was no way of controlling the temperature and the relative humidity of the laboratory [15].

Kumar et al. used the potentiometer adjustment techniques. A common schematic diagram of all electrochemical sensors calibration circuits is shown in Fig. 9 [28]. Makadmini and Horn developed a self-calibrating technique for electrochemical sensors [55]. Chuch and Hatfield presented self-calibrating techniques for the sensors [73]. Kolen described and developed a self-calibration/compensation technique for microcontroller based sensor arrays [75]. This procedure was applied to a four strain gauge system and reduced the residual error to \pm 1 least significant bit (LSB) over most of the target temperature zone. The technique can be universally applied to any sensor array/microcontroller combination provided the required EEPROM, m-bit A/D converter, and k-bit D/A converter [75]. Li et al. presented a calibration technique based on the use of a microcontroller. The application of this technique in a smart capacitive angular position sensor results in self-calibration. For the multiplicative and offset calibrations of the inaccuracy caused by geometrical errors and pattern error of electrodes, only two simple linear fit formulas and seven correction data are required. Experimental results show that this selfcalibration is relatively effective in reducing the inaccuracy caused by the geometrical errors and pattern errors of the sensor [76].

Warmack and Britton presented a method and apparatus for self-calibration of capacitive sensors [77]. Wong presented a technique for self-calibration of an non-destructive infrared (NDIR) gas sensor [78]. Ramesh presented a self-calibration method for gas flow sensor [79].

\section{CONCLUSION}

A review of the literature on environmental monitoring systems elucidates that the existing systems suffer from several drawbacks and thus modifications are being continuously suggested.

The available environmental monitoring systems have limitations as air quality and environmental parameters can not be measured simultaneously. So there is a need for a system which can measure air quality and environmental parameters; in addition, it should be energy efficient, economical, robust, and easy to operate. We found that electrochemical sensorbased STIM modules have many advantages including low power consumption, and lower cost than semiconductor and catalytic bead sensor-based STIM modules. But semiconductor sensor based STIM modules have some advantages including fast response time, and longer life time than electrochemical sensor-based STIM modules.

The functioning of the STIM is controlled by a NCAP and its functioning is not displayed on the liquid crystal display (LCD), and therefore is not capable of error reporting. Moreover, the interface between the STIM and the NCAP is based on a parallel port so it needs greater number of transmission lines and can not be used for long distance communication. For the efficient functioning of the system, it is required that communication and speed of data transfer between the STIM and the NCAP should not depend on the number and type of channels. To make this system work faster and more efficiently, the TII module needs upgrading. Transducer electronic data sheet (TEDS) memory can be used to store data concerning the characteristics of respective sensors, but most of the time this memory has low capacity so it is advisable to use expandable memory. The GUI module developed is based on $\mathrm{C}, \mathrm{C}++$, $\mathrm{C \#}$, and MATLAB tools and is required in a real-time software environment. Real time working of an instrument requires that the GUI must record the graphical waveform of air quality and environmental parameters, but the existing instruments with a GUI fail to do so. Most of the existing instruments used factory-based sensor calibration, but it is not the exact calibration of the entire system. Therefore there is a need to have full instrument calibration.

Real time processing applications that are highly dependent on data often suffer from the problem of missing input variables. These missing data are the main reasons limiting reliability of environmental monitoring systems. They may be missing because one or more than one sensor may have temporarily malfunctioned or because of a data transfer problem of the transducer independent interface. 
In the current version of the EMS, the STIM is working under the control of a NCAP. The system can be further improved by developing a "wireless link" between the STIM and the NCAP. This will be very useful for remote monitoring and control of air pollution parameters without human intervention. The IEEE P1451.5 wireless standard can be used for the development of this system. The designed and developed Indoor Environment Monitoring (IEM) system needs to be put through some remote sensing field tests and not only tests under laboratory conditions. The NCAP program currently controls the STIM with $1000 \mathrm{~kb} / \mathrm{s}$ fixed clock rate. This clock rate should be improved by receiving the direct PC clock rates. In the current version of the environmental monitoring system, the STIM is working under the control of the NCAP. However, if the STIM is improved with an LCD display unit and memory, it can be used as a standalone portable instrument.

\section{REFERENCES}

[1] "UNEP sustainable buildings and climate initiative (SBCI)," United Nations Environmental Programme report, Tech. Rep., 2009.

[2] "AWO Asia and world outlook," Institute of Energy Economics, Tokyo, Japan, Tech. Rep., 2007.

[3] R. K. Pachauri and A. Reisinger, "Climate change 2007-impacts, adaptation and vulnerability," Contribution of Working Group II to the 4th Assessment Report of the IPCC, IGeneva, Switzerland, Rep. 1352, 2007.

[4] "IEO international energy outlook," Energy Information Administration, Washington, DC, Tech. Rep., 2009.

[5] "Indoor environment monitoring," ASHRAE Hand Book, Hong Kong: ASHRAE, 2001, ch. 9, pp. 9.1-9.20.

[6] C. K. Chau, W. K. Hui, and M. S. Tse, "Evaluation of health benefits for improving indoor air quality in work place," Environ. Int., vol. 33, no. 2, pp. 186-198, 2007.

[7] W. S. Cain, J. M. Samet, and M. J. Hodgson, "The quest for negligible health risks from indoor air," ASHRAE J., vol. 37, no. 7, p. 38, 1995.

[8] G. Hoek, B. Brunekreef, S. Goldbohm, P. Fischer, and P. A. Brandt, "Association between mortality and indicators of traffic-related air pollution in the Netherlands: A cohort study," Lancet vol. 360, no. 9341, pp. 1184-1185, Oct. 2002.

[9] J. F. Nicol and M. A. Humphreys, "Adaptive thermal comfort and sustainable thermal standards for buildings," Energy Build., vol. 34, no. 6, pp. 563-572, 2002.

[10] G. S. Brager and R. J. Dear, "Thermal adaptation in the built environment: A literature review," Energy Build., vol. 27, no. 1, pp. 83-96, 1998.

[11] M. Fountain, G. Brager, and R. J. Dear, "Expectations of indoor climate control," Energy Build., vol. 24, no. 3, pp. 179-182, 1996.

[12] Thermal Environmental Conditions for Human Occupancy, American Society of Heating, Refrigerating and Air-conditioning Engineers Inc., ASHRAE 55, 2004.

[13] A. Kumar, I. P. Singh, and S. K. Sud, "Development of multi-channel data logger for indoor environment," J. Eng., vol. 2, no. 9, pp. 690-697, 2010.

[14] C. Arnold, M. Harms, and J. Goschnick, "Air quality monitoring and fire detection with the Karlsruhe electronic micronose KAMINA," IEEE Sensors J., vol. 2, no. 3, pp. 179-188, Jun. 2002.

[15] N. Kularatna and B. H. Sudantha, "An environmental air pollution monitoring system based on the IEEE 1451 standard for low cost requirements," IEEE Sensors J., vol. 8, no. 4, pp. 415-422, Apr. 2008.

[16] F. Sarry and M. Lumbreras, "Gas discrimination in air-conditioned system," IEEE Trans. Instrum. Meas., vol. 49, no. 4, pp. 809-812, Apr. 2000.

[17] H. M. G. Ramos, J. M. D. Pereria, V. Viegas, O. Postolache, and P. M. B. S. Girao, "A virtual instrument to test smart transducer interface modules (STIMS)," IEEE Trans. Instrum. Meas., vol. 53, no. 4, pp. 1232-1239, Apr. 2004.

[18] D. Grimaldi and M. Marinov, "Distrebuted measurement system," Measurement, vol. 30, no. 4, pp. 279-287, 2001.

[19] D. D. Lee and D. S. Lee, "Environment gas sensors," IEEE Sensors J., vol. 1, no. 3, pp. 214-215, Oct. 2001.
[20] P. O. Fanger, "Thermal environment - human requirements," Environmentalist, vol. 6, no. 4, pp. 275-278, 1986.

[21] Y. Kim, R. G. Evans, and W. M. Iversen, "Remote sensing and control of an irrigation system using a distributed wireless sensor network," IEEE Trans. Instrum. Meas., vol. 57, no. 7, pp. 1379-1387, Jul. 2008.

[22] H. C. Lee, A. Banerjee, Y. M. Fang, B. J. Lee, and C. T. King, "Design of a multifunctional wireless sensor network for in situ monitoring of debris flows," IEEE Trans. Instrum. Meas., vol. 59, no. 11, pp. 2958-2967, Nov. 2010.

[23] A. Carullo, S. Corbellini, M. Parvis, and A. Vallan, "A wireless sensor network for cold chain monitoring," IEEE Trans. Instrum. Meas., vol. 58, no. 5, pp. 1405-1411, May 2009.

[24] A. Lay-Ekuakille and A. Trotta, "Predicting VOC concentration measurements: Cognitive approach for sensor networks," IEEE Sensors J., vol. 5, no. 11, pp. 3923-3030, Nov. 2011.

[25] A. Lay-Ekuakille, P. Vergallo, N. I. Giannoccaro, A. Massaro, and D. Caratelli, "Prediction and validation of outcomes from air monitoring sensors and networks of sensors," in Proc. 5th Int. Conf. Sensing Technol., Nov.-Dec. 2011, pp. 73-78.

[26] IEEE Standard for a Smart Transducer Interface for Sensors and Actuators - Transducer to Microprocessor Communication Protocols and Transducer Electronic Data Sheet (TEDS) Formats, IEEE standard 1451.2, 1997.

[27] IEEE Standard for a Smart Transducer Interface for Sensors and Actuators-Network Capable Application Processor (NCAP) Information Model, IEEE standard 1451.1, 1999.

[28] A. Kumar, I. P. Singh, and S. K. Sud, "Energy efficient and low cost indoor environment monitoring system based on the IEEE 1451 standard," IEEE Sensors J., vol. 11, no. 10, pp. 2598-2610, Oct. 2011.

[29] M. A. Abas, M. H. Fadzil, and A. K. Hakiim, "Development of environmental monitoring data management system using OSS python," World Academy Sci., Eng. Technol., vol. 64, pp. 180-185, Sep. 2010.

[30] J. B. Miller, "Catalytic sensors for monitoring explosive atmospheres," IEEE Sensors J., vol. 1, no. 1, pp. 88-93, Jun. 2001.

[31] "Solid state gas sensors," in International Sensor Technology. Mountain View, CA: IST, ch. 4, pp. 47-52, 2009.

[32] "Infrared gas sensors," in International Sensor Technology. Mountain View, CA: IST, ch. 5, pp. 55-71, 2008.

[33] "Photoionization detectors," in International Sensor Technology. Mountain View, CA: IST, ch. 6, pp. 73-81, 2009.

[34] D. M. Wilson, S. Hoyt, J. Janata, K. Booksh, and L. Obando, "Chemical sensors for portable, hand held field instruments," IEEE Sensors J., vol. 1, no. 4, pp. 256-274, Dec. 2001.

[35] "Sensor selection guide," in International Sensor Technology. Mountain View, CA: IST, ch. 8, pp. 103-109, 2010.

[36] C. Lee, N. Szabo, R. Ramamoorthy, P. Dutta, and S. Akbar, "Solid state electrochemical sensors," Encyclopedia Sensors, vol. 10, pp. 1-20, Mar. 2006.

[37] "Electrochemical sensors," in International Sensor Technology. Mountain View, CA: IST, ch. 2, pp. 27-35, 2008.

[38] V. Nandakumar, D. Bishop, E. Alonnas, J. Labelle, L. Joshi, and T. L. Alford, "A low cost electrochemical biosensor for rapid bacterial detection," IEEE Sensors J., vol. 11, no. 1, pp. 210-216, Jan. 2011.

[39] "Electrochemical sensors for environment monitoring: A review of recent technology," (Mar. 2005) U.S. Environment Protection Agency [Online]. Available: http//www.epa.gov

[40] J. Wang, "Modified electrodes for electrochemical sensors," Electroanalysis, vol. 3, nos. 4-5, pp. 255-259, Jun. 1991.

[41] U. Yogeswaran and S. M. Chen, "A review on the electrochemical sensors and biosensors composed of nanowires as sensing material," Sensors, vol. 8, no. 1, pp. 290-313, 2008.

[42] Alphasense sensors data sheet, Shielding toxic sensors from electromagnetic interface, no. 12. Great Notley, U.K., Alphasense Ltd., Sensor Technology House, 2005.

[43] E. Bakker and Y. Qin, "Electrochemical sensors," Anal. Chem., vol. 78, no. 12 , pp. 3965-3984, 2006

[44] P. R. Warburton, M. P. Pagano, R. Hoover, M. Logman, and K. Crytzer, "Amperometric gas sensor response time," Anal. Chem., vol. 70, no. 5, pp. 998-1006, 1998.

[45] F. Estini, "Electrochemical sensor: kit comprising said sansor and processor for the production," 2001 [Online]. Available: http://www.Faqs.org/patents/ app/20080251393

[46] Alphasense sensors data sheet, how electrochemical sensors work, no. 12. Great Notley, U.K., Alphasense Ltd., Sensor Technology House, 2005. 
[47] D. E. Garcia, T. H. Chen, F. Wei, and C. M. Ho, "A parametric design study of an electrochemical sensors," J. Assoc. Lab. Autom., vol. 15, no. 3, pp. 179-188, Jun. 2010.

[48] "Designing a potentiostatic circuit," Alphasense Sensors Data Sheet. Great Notley, U.K.: Alphasense Ltd., Sensor Technology House, 2009.

[49] M. Acosta, "Designing with electrochemical sensor," National Semiconductor Company, Santa Clara, CA, (2008) [Online]. Available: $\mathrm{http} / / \mathrm{www}$.national.com/nationaledge/files/nationalAN-1798

[50] J. W. Gardner, P. K. Guha, F. Udrea, and J. A. Covington, "CMOS interfacing for integrated gas sensors: A Review," IEEE Sensors J., vol. 10, no. 12, pp. 1833-1848, Dec. 2010.

[51] H. Xie and Y. Liu, "Design of air-conditioning control system in university gymnasium based on virtual instrument technology," in Proc. IEEE 2nd Int. Conf. Comput. Eng. Technol., Apr. 2010, pp. 321-325.

[52] S. R. Rossi, A. A. Carvalho, A. C. R. Silva, E. A. Batista, C Kitano, T. A S. Filho, and T. A. Prado, "Open and standardized resources for smart transducer networking," IEEE Trans. Instrum. Meas., vol. 58, no. 10, pp. 3754-3761, Oct. 2009.

[53] D. Perrussel, "Open sensor interface needs for the US Navy," U.S., Navy Open Sensors/Interfaces-Sensors Expo 2005, Dahlgren, VA, Jun. 2005.

[54] "NI plug and play sensors program," IEE Computing and Control Engineering, (Mar. 2005) [Online]. Available: http://digital.ni.com/worldwide/portugal.nsf/webproduct

[55] L. Makadmini and M. Horn, "Self calibrating electrochemical gas sensor," in Proc. Int. Conf. Solid State Sensors Actuators, Jun. 1997, pp. 299-302.

[56] Y. S. Chan, A. Tantram, S. Desmond, and B. Hobbs, "MPEP patent," U.S. Patent: 4132616 , Mar. 1996.

[57] "IST gas sensors calibration," in International Sensor Technology, CA, ch. 11, pp. 161-173, 2005.

[58] R. Kochan, K. Lee, V. Kochan, and A. Sachenko, "Development of a dynamically reprogrammable NCAP," in Proc. IEEE 21st Conf. Instrum. Meas. Technol., May 2004, pp. 1188-1193.

[59] L. Camara, O. Ruiz, A. Herms, J. Samitier, and J. Bosch, "Automatic generation of intelligent instruments for IEEE 1451," Measurement, vol. 35, no. 1, pp. 3-9, Aug. 2004.

[60] L. Camara, J. M. Gomez, J. Samitier, and J. Bosch, "Smart transducer systems working in communication networks within the IEEE-1451 standard," in Proc. IEEE 28th Annu. Conf. Ind. Electron. Soc., Nov. 2002, pp. 2898-2902.

[61] L. Bissi, P. Placidi, A. Scorzoni, I. Elim, and S. Zampalli, "Environmental monitoring system compliant with IEEE 1451 standard and featuring a simplified transducer interface," Sens. Actuators A, vol. 137, no. 1, pp. 175-184, May 2007.

[62] N. Ulivieri, C. Distante, T. Luca, S. Rocchi, and P. Siciliano, "IEEE 1451.4: A way to standardize gas sensor," Sens. Actuators B, vol. 114, no. 1, pp. 141-151, Oct. 2006.

[63] T. Radu, C. Fay, K. T. Lau, R. Waite, and D. Diamond, "Wearable sensing application-carbon dioxide monitoring for emergency personal using wearable sensors," World Academy Sci., Eng. Technol., vol. 58, pp. 80-82, Nov. 2009.

[64] A. Pardo, L. Camara, J. Cabre, A. Rerera, X. Cano, S. Marco, and J. Bosch, "Gas measurement systems based on IEEE 1451.2 standard," Sens. Actuators B, vol. 116, no. 1, pp. 11-16, Mar. 2006.

[65] R. Mukaro and X. F. Carelse, "A microcontroller based data acquisition system for solar radition and environment monitoring," IEEE Trans. Instrum. Meas., vol. 4, no. 6, pp. 1232-1238, Jul. 1999.

[66] O. J. Sung and W. Y. Chung, "Room environment monitoring system from PDA terminal," in Proc. IEEE Int. Symp. Intell. Signal Proc. Commun. Syst., Nov. 2004, pp. 497-501.

[67] L. Camara, O. Ruiz, and J. Samitier, "Complete IEEE-1451 node, STIM and NCAP, implemented for a CAN network," in Proc. IEEE 17th Int. Conf. Instrum. Meas. Technol., May 2000, pp. 541-545.

[68] R. Mukaro and X. F. Carelse, "A serial communication program for accessing a microcontroller-based data acquisition system," Comput. Geosci., vol. 23, no. 9, pp. 1027-1032, 1997.

[69] H. Ramos, M. Pereira, V. Viegas, O. Postolache, and P. Girao, "A centronics based transducer independent interface (TII) fully compliant with 1451.2 Std.," in Proc. Portuguese Sci. Technol. Foundat. Program, Oct. 2002, pp. 1-9.

[70] P. Conway, D. Heffernan, B. O. Mera, P. Burton, and T. Miao, "IEEE 1451.2: An interpretation and example implementation," in Proc. IEEE 17th Int. Conf. Instrum. Meas. Technol., May 2000, pp. 535-540.

[71] D. S. Lee, H. Y. Jung, J. W. Lim, M. Lee, S. W. Ban, J. S. Huh, and D. D. Lee, "Explosive gas recognition system using thick film sensor array and neural network," Sens. Actuators B, vol. 71, pp. 90-98, Sep. 2000.
$72]$ D. S. Lee, J. K. Jung, J. W. Lim, J. S. Huh, and D. D. Lee, "Recognition of volatile organic compounds using $\mathrm{SnO}_{2}$ sensor array and pattern recognition analysis," Sens. Actuators B, vol. 77, pp. 228-236, Jun. 2001.

[73] H. T. Chuch, and J. V. Hatfield, "A real-time data acquisition system for a hand held electronic nose $\left(\mathrm{H}^{2} \mathrm{EN}\right)$," Sens. Actuators B, vol. 83, pp. 262-269, Feb. 2002.

[74] J. W. Gardner and D. C. Dyer, "Interface electronics and sensor systems high-precision intelligent interface for a hybrid electronic nose," Sens. Actuators A, vol. 62, pp. 724-728, Aug. 1997.

[75] P. T. Kolen, "Self calibration/compensation technique for microcontroller based sensor arrays," IEEE Trans. Instrum. Meas., vol. 43, no. 4, pp. 620-623, Aug. 1994.

[76] X. Li, C. M. Meijer, and G. W. Jong, "A microcontroller-based selfcalibration technique for a smart capacitive angular-position sensor," IEEE Trans. Instrum. Meas., vol. 46, no. 4, pp. 1-5, Aug. 1997.

[77] R. J. Warmack and C. L. Britton, "Method and apparatus for self calibration of capacitive sensor," U.S. Patent 6545 495, Oct. 2003.

[78] J. Y. Wong, "self-calibration of an NDIR gas sensor," U. S. Patent 5347474, Jun. 1994.

[79] A. K. Ramesh, "Gas flow sensor system and method for self calibration," U. S. Patent 7243538, May 2007.

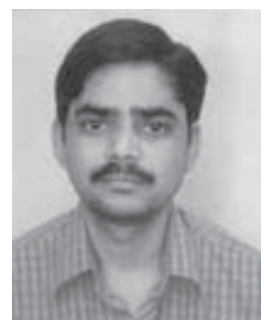

Anuj Kumar received the M.Phil. from the Indian Institute of Technology Roorkee, Roorkee, India, and the M.Tech. degree from the National Institute of Technology Kurukshetra, India, in 2000 and 2004, respectively, both in instrumentation, and the Ph.D. degree in embedded systems from the Indian Institute of Technology Delhi, New Delhi, India, in 2011.

He was with APL Intelligent Embedded, New Delhi, where he was involved in the development of microcontroller-based applications from 2000 to 2002. In 2004, he joined DellSoft Technologies, New Delhi, as an Instrumentation Engineer - EDA. In 2012 (January-October), he was a Post-Doctoral Research Fellow with the Electrical and Computers Engineering Department, University of Seoul, Korea. Since November 2012, he has been the ViceChancellor Post-Doctoral Fellow with the Department of Electrical, Electronic and Computer Engineering, University of Pretoria, Pretoria, South Africa. His current research interests include smart sensing systems, intelligent systems, microcontroller-based applications, and instrumentation electronics.

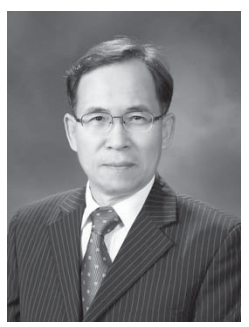

Hiesik Kim was born in 1953 in Kyoung-Ju, Korea. He received the Bachelor's degree in mechanical engineering from Seoul National University, Seoul, Korea, in 1977, a Master's degree in production engineering from the Korea Advanced Institute of Science and Technology (KAIST), Daejeon, Korea, and the Doctorate (Doktor-Ingenieur) degree in production engineering (FhG-IPA) from Stuttgart University, Stuttgart, Germany, in 1987, under the supervision of Prof. Dr.-Ing. H.-J. Warnecke.

He was a Technical Official with the Ministry of Science and Technology of the Korean Government from 1979 to 1982 and as Senior Researcher with the CAD/CAM Research Laboratory, KAIST from 1987 to 1989. Since 1989, he has been a Professor with the Department of Electrical and Computer Engineering, University of Seoul, Seoul. He was the Vice Dean with the Engineering College. His current research interests include optical measurement of geometries, applications of sensors for automation and image processing.

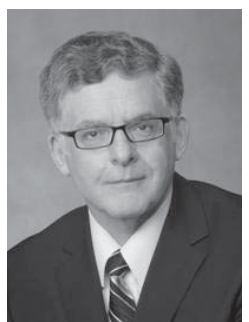

Gerhard P. Hancke (M'88-SM'00) received the B.Sc., B.Eng. and M.Eng. degrees from the University of Stellenbosch, South Africa, and the D.Eng. degree from the University of Pretoria, South Africa, in 1983 .

He is currently a Professor and Coordinator of the Computer Engineering Program in the Department of Electrical, Electronic and Computer Engineering, University of Pretoria, responsible for curriculum development and administration of the program. He leads the Group of Advanced Wireless Sensor. $\mathrm{He}$ partakes extensively in collaborative research programs with research institutions internationally. $\mathrm{He}$ is a Professional Engineer and held offices in various national and international scientific and professional bodies. His research interests include advanced sensor and actuator networks. 